\title{
D-Galactose Induced Changes in Enzymatic Antioxidant Status in Rats of Different Ages
}

\author{
N. HADZI-PETRUSHEV ${ }^{1}$, V. STOJKOVSKI ${ }^{2}$, D. MITROV ${ }^{2}$, M. MLADENOV ${ }^{1}$ \\ ${ }^{1}$ Faculty of Natural Sciences and Mathematics, Institute of Biology, "Ss. Cyril and Methodius" \\ University, Skopje, Macedonia, ${ }^{2}$ Faculty of Veterinary Medicine, "Ss. Cyril and Methodius" \\ University, Skopje, Macedonia
}

Received March 26, 2014

Accepted July 28, 2014

On-line September 5, 2014

\begin{abstract}
Summary
Considering the preexisting influence of the process of natural aging on antioxidant enzymes activity and the level of lipid peroxidation, the age of the rats at which D-galactose (D-gal) treatment is started could strongly impact the development of D-gal induced senescence. To evaluate this, we subjected 1, 3 and 15 months old rats to D-gal treatment in parallel with having appropriate placebos ( $0.9 \%$ saline). Our results showed elevated glutathione peroxidase (GPx) activity and no significant changes in superoxide dismutase (SOD), catalase (CAT) and glutathione reductase (GR) activity or malondialdehyde (MDA) levels in relation to natural aging. In mature and aged senescent livers we observed positive correlation between increased ratio $R=\mathrm{SOD} /(\mathrm{GPX}+\mathrm{CAT})$ and increased MDA concentration. MDA levels seemed to correlate positively with the age of the animals at which D-gal treatment had started. In the case of 3 and 15 months old rats there was D-gal induced decrease in SOD and GR activity, but this effect of the treatment was not observed in 1 month old rats. Our results imply that the changes in the antioxidant enzyme activities are not only under the influence of the D-gal overload, but also depend on the developmental stage of the rats. According to our results, with regard to enzymatic antioxidant capacity and the level of lipid peroxidation, the best age for induction of senescence is somewhere after the third month.
\end{abstract}

\section{Key words}

D-Galactose • Senescence • Aging • Antioxidant enzymes • Lipid peroxidation $\bullet$ Wistar rats

\section{Corresponding author}

N. Hadzi-Petrushev, Faculty of Natural Sciences and Mathematics, Institute of Biology, "Ss. Cyril and Methodius" University, P.O. Box 162, 1000 Skopje, Macedonia. E-mail: nikola@pmf.ukim.mk

\section{Introduction}

Aging is a multifactorial process associated with physiological decline. There is a substantial amount of data supporting the positive relation between the process of aging and the progressive decline in antioxidant function combined with increased mitochondrial ROS (reactive oxygen species) generation and increased accumulation of oxidant products (Tian et al. 1998, Kasapoglu and Ozben 2001, Navarro et al. 2004). Some of these products are generated by the process of lipid peroxidation that involves the oxidative deterioration of polyunsaturated fatty acids from the cell membranes (Mladenov et al. 2006). The ROS-derived unstable lipid peroxides disintegrate to different products including carbonyl compounds like malondialdehyde (MDA). The measurement of MDA is a reliable method for assessment of the level of lipid peroxidation and it is one of the most important biomarkers of aging (Pandey and Rizvi 2010).

On the other hand, the most important line of defense is represented by the main antioxidant enzymes. The three isoforms of superoxide dismutase (SOD) are responsible for the elimination of superoxide anions, the most abundant form of ROS, produced mainly during electron transfer in the mitochondrial respiratory chain (Halliwel 1991). As a result of this action, hydrogen 
peroxide is generated and it can be further neutralized by the activity of catalase (CAT). Hydrogen peroxide can be reduced by glutathione peroxidase (GPx), an enzyme that functions as part of the glutathione cycle, along with glutathione reductase (GR). However, conflicting results do exist and the association between antioxidant status, lipid peroxidation and aging, seems to display variations depending on the species, strain, sex and examined organs of the experimental animals (Rikans and Hornbrook 1997).

Animal models provide valuable research tools toward a better understanding of the mechanisms underlying aging. A process very similar to natural aging can be induced by chronic administration of D-galactose (D-gal) (Ho et al. 2003). An oversupply of D-gal leads to its conversion to D-galacto-hexodialdose and hydrogen peroxide by galactose oxidase and to galactitol by action of aldose reductase (Ho et al. 2003). These products can accumulate in cells, which in turn causes osmotic and oxidative stress that may account for the acceleration of aging (Kumar et al. 2011). Hence rodents treated with D-gal can be used as an animal model for oxidative stress. That is based on one of the proposed mechanisms of D-gal induced senescence, known to involve increased production of oxidants, changes in antioxidant enzymes activity and accumulation of oxidative damage (Wei et al. 2005, He et al. 2009). The described processes could be responsible for altered antioxidant capacity and increased MDA production, which has been registered in studies involving D-gal induced aging (Anand et al. 2012, Banji et al. 2013, Liu et al. 2013). Most of the studies involving D-gal accelerated aging are performed using mice and less frequently rats as experimental animals, and they are mainly focused on the neurodegenerative changes.

In view of the relative lack of data regarding D-gal induced aging in rats and considering the preexisting influence of the process of natural aging on antioxidant enzymes activity, we hypothesized that the age of the rats at which D-gal treatment is started, could strongly impact the development of D-gal induced senescence. This might lead to animal models with varying antioxidant status, irrespective of the equal D-gal dose and treatment duration. Therefore, one of the aims of our study was to provide data about the antioxidant enzymes activity in rats of different age, subjected to both natural and D-gal induced aging. We also determined the concentration of MDA, to confirm the impact of altered enzymatic antioxidant capacity on the level of lipid peroxidation in the liver and kidney of the experimental animals, since these tissues are both metabolically active and show age-related increase in the level of lipid peroxidation products (Ward 2005).

Furthermore, taking into account our previous studies (Hadzi-Petrushev et al. 2011, Stojkovski et al. 2013), where we published that sensitivity to free radicals apparently depends on the equilibrium between the formation of hydrogen peroxide from superoxide (in the dismutation reaction catalyzed by SOD) and its degradation by GPx and CAT, rather than on the activities of individual antioxidant enzymes, we lay down the basis for the second aim of this study, which is to investigate the relationship between the ratio of activities of antioxidant enzymes $R=\mathrm{SOD} /(\mathrm{GPx}+\mathrm{CAT})$ and the levels of MDA in the liver and kidney of D-gal treated rats. Additionally, considering the sex-dependent reactions on various stressors, the presented methods could also be important in further studies regarding the development of D-gal induced senescence in rats of different gender.

\section{Material and Methods}

\section{Animals and experimental design}

All experimental procedures were conducted in accordance with the Guiding Principles for Care and Use of Laboratory Animals approved by the Macedonian Center for Bioethics. All protocols were approved by the Animal Ethics Committee of the University "Ss. Cyril and Methodius", Skopje, R. Macedonia, in accordance with the International Guiding Principles for Biomedical Research Involving Animals. Anesthetics were applied according to the standards given by the guide of the EC Directive 86/609/EEC. Animals were anesthetized with an intraperitoneal injection of thiopental sodium (RhonePoulenc Rorer Limited, Nenagh, Co Tipperary, Ireland), $50 \mathrm{mg} \mathrm{kg}^{-1}$ b.wt. Male Wistar rats $(\mathrm{n}=48)$ were used for all protocols and were maintained on a 12:12 light:dark cycle and fed with standard rat chow and water ad libitum.

All animals were divided into six groups (each containing 8 rats) depending on their age and treatment with D-gal. The process of induction of aging usually involves administration of $50-500 \mathrm{mg} / \mathrm{kg}$ D-gal for 6-8 weeks (Kumar and Rizvi 2014). Three groups consisted of placebo $(0.9 \%$ saline, $1.5 \mathrm{ml}$ daily, subcutaneous) rats, at the age of 1 month ("young"), 
3 months ("mature") and 15 months ("aged"). The other three groups of animals, starting at the same age, for 42 consecutive days were treated with D-galactose (Sigma, St Louis, MO, USA), $300 \mathrm{mg} \mathrm{kg} \mathrm{kg}^{-1}$ b.wt., subcutaneous, daily.

\section{Tissue preparation}

The livers and kidneys were excised during laparotomy. Immediately upon collection all tissue samples were washed with physiological salt solution and then were snap-frozen in liquid nitrogen and stored at $-80{ }^{\circ} \mathrm{C}$ until further analysis.

\section{Assay for SOD activity}

SOD activity was determined according to the method described by Marklund and Marklund (1974), based on the ability of SOD to inhibit the autooxidation of pyrogallol. The reaction mixture consisted of $50 \mathrm{mM}$ Tris- $\mathrm{HCl}, \mathrm{pH} 8.2,1 \mathrm{mM}$ diethylenetriamine pentaacetic acid and sample. The reaction was initiated by the addition of pyrogallol (final concentration of $0.2 \mathrm{mM}$ ) and the absorbance measured kinetically at $420 \mathrm{~nm}$, $25^{\circ} \mathrm{C}$, for $3 \mathrm{~min}$. One unit of activity is defined as the amount of sample needed to inhibit pyrogallol oxidation by $50 \%$. The final results were expressed as $\mathrm{U} / \mathrm{mg}$ protein.

\section{Assay for CAT activity}

CAT activity was determined by measuring the degradation of hydrogen peroxide $\left(\mathrm{H}_{2} \mathrm{O}_{2}\right)$, using the method described by Claiborne (1985). The reaction mixture $(1 \mathrm{ml})$ consisted of $50 \mathrm{mM}$ potassium phosphate buffer, $\mathrm{pH} 7.0,19 \mathrm{mM} \mathrm{H}_{2} \mathrm{O}_{2}$ and sample. The reaction was initiated by the addition of $\mathrm{H}_{2} \mathrm{O}_{2}$ and the change in absorbance was followed at $240 \mathrm{~nm}, 25^{\circ} \mathrm{C}$, for a time period of $30 \mathrm{~s}$, taking measurements at $5 \mathrm{~s}$ intervals. In those conditions, the molar extinction coefficient for $\mathrm{H}_{2} \mathrm{O}_{2}$ is $43.6 \mathrm{M}^{-1} \mathrm{~cm}^{-1}$. The activity of CAT was expressed as $\mathrm{U} / \mathrm{mg}$ protein, with one unit of activity being equal to the conversion of $1 \mu \mathrm{mol} \mathrm{H}_{2} \mathrm{O}_{2}$ per minute.

\section{Assay for GPx activity}

The activity of GPx was determined according to the method described by Lawrence and Burk (1976). The activity was assayed by following the oxidation of $\mathrm{NADPH}$ at $340 \mathrm{~nm}$ for $3 \mathrm{~min}, 25^{\circ} \mathrm{C}$, in the presence of GR and GSH. The reaction mixtures containing $50 \mathrm{mM}$ potassium phosphate, $\mathrm{pH} 7.0,1 \mathrm{mM}$ sodium azide, $2 \mathrm{mM}$
GSH, $0.2 \mathrm{mM}$ NADPH, $1 \mathrm{U} / \mathrm{ml}$ GR, $1.5 \mathrm{mM}$ cumene hydroperoxide and sample, were incubated at $25^{\circ} \mathrm{C}$ for $5 \mathrm{~min}$. The reaction was initiated by the addition of cumene hydroperoxide. One unit of activity was defined as the oxidation of $1 \mu \mathrm{mol}$ of NADPH per minute. Final results were expressed as $\mathrm{U} / \mathrm{mg}$ protein.

\section{Assay for GR activity}

The rate of oxidation of NADPH by GSSG at $30{ }^{\circ} \mathrm{C}$ was used as a measure of GR activity (Racker 1955). The reaction system contained $1 \mathrm{mM}$ GSSG, $0.1 \mathrm{mM}$ NADPH, $0.5 \mathrm{mM}$ EDTA, $100 \mathrm{mM}$ potassium phosphate buffer, $\mathrm{pH} 7.5$, and sample. The oxidation of $1 \mu \mathrm{mol}$ of NADPH per minute was defined as a unit of GR activity. The specific activity was expressed as $\mathrm{mU} / \mathrm{mg}$ protein.

The protein content of the liver and kidney samples was determined using the method described by Lowry et al. (1951).

\section{Malondialdehyde assay}

The lipid peroxides were estimated in the liver and kidney homogenates using the thiobarbituric acid (TBA) reactive substances tests, described by Ohkawa et al. (1979). After the addition of $8.1 \%$ sodium dodecyl sulfate, each sample or standard (1,1,3,3tetraethoxypropane solution) was vortexed and left at room temperature for $10 \mathrm{~min}$. At the end of the incubation period, $20 \%$ acetic acid and $0.6 \%$ thiobarbituric acid were added and the test tubes were placed in a water bath at $90-95^{\circ} \mathrm{C}$ for $1 \mathrm{~h}$. After that, they were cooled on ice and the colored supernatant was obtained by adding a mixture of butanol:pyridine (15:1), vortexing and centrifuging. The absorbance was measured at $535 \mathrm{~nm}$. The results were expressed as nmol MDA per $\mathrm{g}$ tissue.

\section{Statistical analysis}

Results are presented as means \pm standard error (SE). The effects of D-gal treatment and aging were assessed using One-way analysis of variance (ANOVA). The post-hoc test of Tukey was performed in selected instances to evaluate further differences between group pairs. Correlations were expressed using the Pearson's product-moment correlation coefficient. All analyses were performed with GraphPad Prism 4.0 (San Diego, CA, USA). $\quad \mathrm{p}<0.05$ was considered statistically significant. 


\section{Results}

Influence of aging and D-gal treatment on SOD activity in liver and kidney

The process of natural aging did not cause significant changes in SOD activity in both liver and kidney, according to the results obtained when comparing the activity of SOD in young placebo (YP) to mature and aged placebo rats (MP and AP, respectively). The treatment with D-gal led to significant decrease in SOD activity, in both liver and kidney of mature and aged rats, but there were no significant changes in the examined tissues of young animals. This was concluded by comparing the SOD activity in the liver of MP to MT (mature treated) rats $(\mathrm{p}<0.001)$, as well as SOD activity in the liver of AP to AT (aged treated) animals ( $<<0.001$ ). The same effect of the treatment was observed when making the equivalent comparisons in kidney (MP to MT, $p<0.05$ and AP to AT, $p<0.01$ ). Additionally, in the young kidney, the lack of effect of D-gal treatment, was further supplemented by the significantly higher SOD activity in YT (young treated) compared to MT and AT rats ( $p<0.01$ in both cases) (Fig. 1).
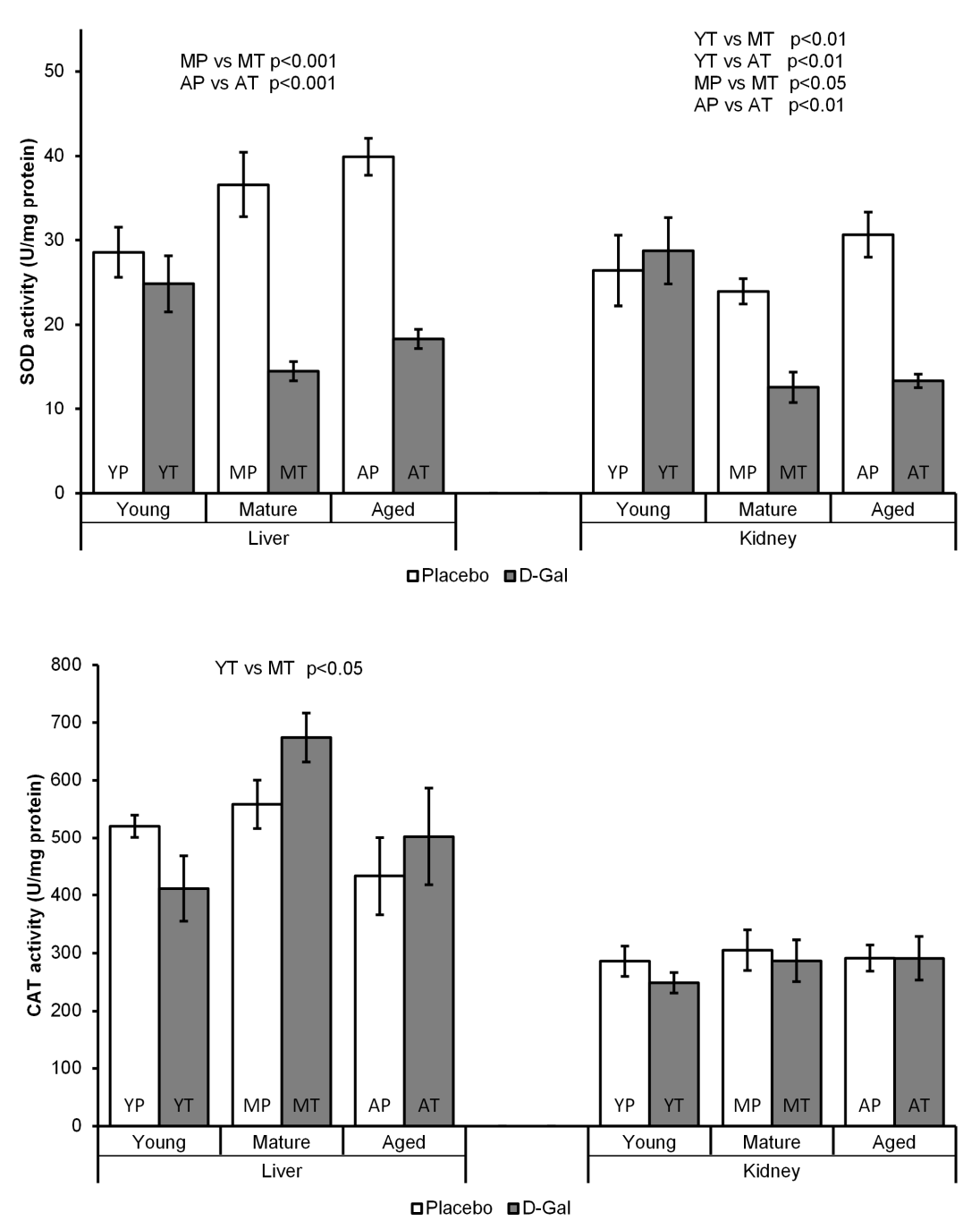

Fig. 1. Superoxide dismutase activity in liver and kidney (SOD, mean $\pm \mathrm{SE}$ ). YP - young placebo treated, YT - young D-gal treated, MP - mature placebo treated, MT - mature D-gal treated, AP - aged placebo treated, AT - aged D-gal treated.

Fig. 2. Catalase activity in liver and kidney $(\mathrm{CAT}$, mean $\pm \mathrm{SE})$. Abbreviations for groups are the same as in Figure 1.
Influence of aging and D-gal treatment on CAT activity in liver and kidney

There were no significant differences in CAT activity in the liver between the groups of YP, MP and AP, respectively. The same situation was observed in the kidney, confirming the nonappearance of significant effects of the process of natural aging on CAT activity.
Similarly, the treatment with D-gal failed to cause significant changes to CAT activity in the liver and kidney, regardless of the age of the rats at the beginning of the treatment. However, CAT activity in the liver of MT was significantly higher compared to the activity in the liver of YT animals ( $<<0.05)$ (Fig. 2). 
Influence of aging and D-gal treatment on GPx activity in liver and kidney

The effect of natural aging on GPx activity was evident only in the kidney, when comparing the activity in YP to AP rats $(p<0.001)$ and MP to AP rats $(p<0.01)$. Increased GPx activity was also observed due to D-gal treatment in the liver of MT and AT rats $(\mathrm{p}<0.05$ in both cases) and in the kidney of MT $(\mathrm{p}<0.05)$. YT had GPx activity in the liver and kidney that was not significantly different than the activity in the appropriate placebo groups. Moreover, GPx activity in the liver of YT rats stayed significantly lower compared to the activity in MT and AT animals ( $p<0.001$ and $\mathrm{p}<0.01$, respectively). In the kidney, GPx activity in YT rats was also significantly lower than the activity in MT and AT rats $(\mathrm{p}<0.001$ in both cases) (Fig. 3).
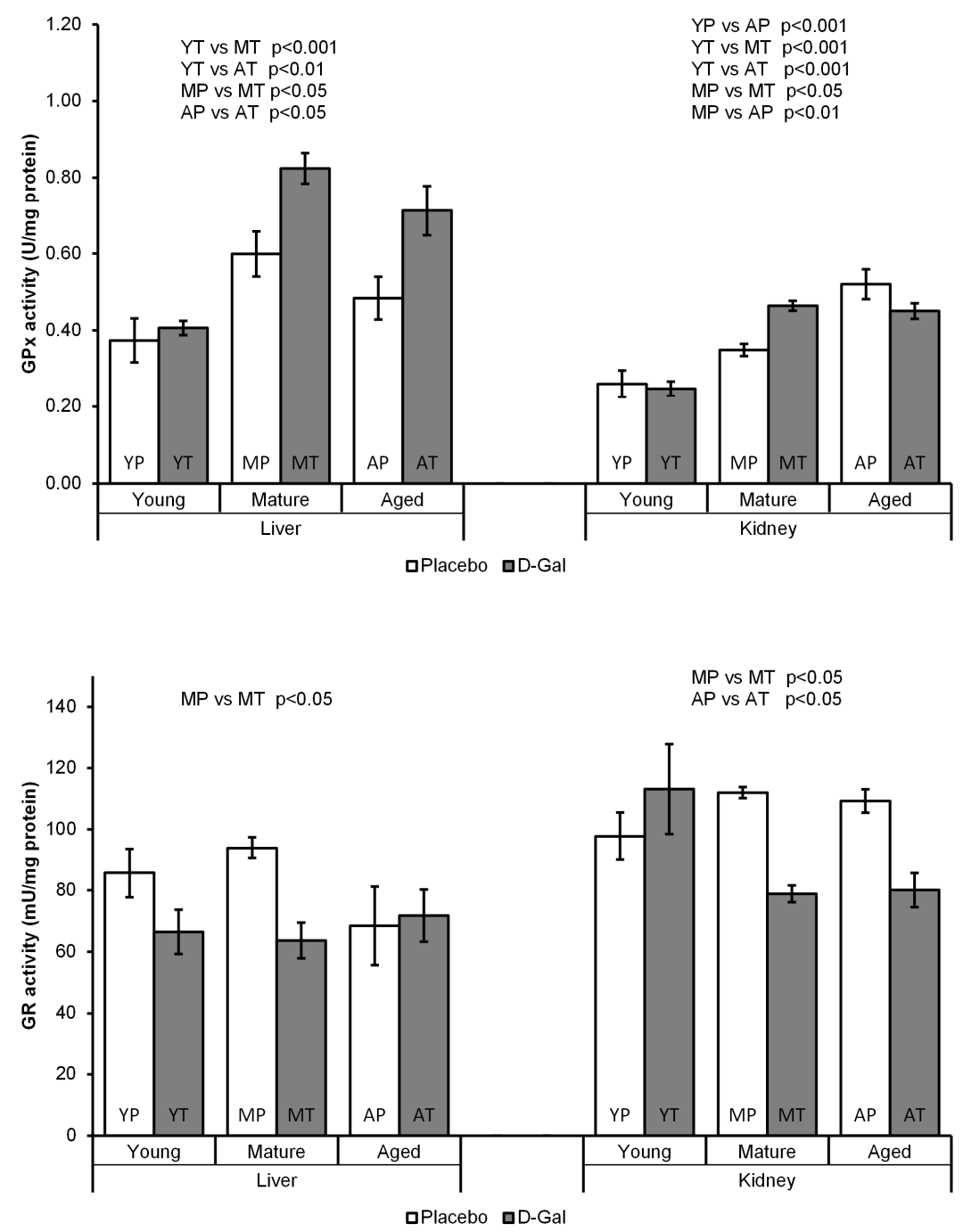

Fig. 3. Glutathione peroxidase activity in liver and kidney (GPx, mean $\pm \mathrm{SE}$ ). Abbreviations for groups are the same as in Figure 1.
Fig. 4. Glutathione reductase activity in liver and kidney (GR, mean $\pm \mathrm{SE}$ ). Abbreviations for groups are the same as in Figure 1.
Influence of aging and D-gal treatment on GR activity in liver and kidney

The data presented on Figure 4, demonstrated that GR activity in the liver and kidney did not change significantly with the age. The treatment with D-gal, resulted in a significant decrease in GR activity in the livers of MT rats $(\mathrm{p}<0.05)$ and in the kidney of MT and AT animals $(p<0.05$ in both cases). GR activity in the liver and kidney of YT rats did not change significantly compared to the placebo groups and at the same time was not significantly different than GR activity in the MT and AT rats.

Influence of aging and D-gal treatment on liver and kidney MDA levels

The results from our study showed that the effects of the process of natural aging were not strong enough to cause significant changes in MDA levels in both liver and kidney. Quite differently, the treatment with D-gal led to a significant increase in MDA 
concentration in the liver and kidney of MT $(\mathrm{p}<0.001$ for liver and $\mathrm{p}<0.05$ for kidney) and AT rats ( $<<0.001$ for both). This effect of D-gal treatment was not observed in the examined tissues of young rats. The MDA levels seemed to correlate positively with the age of the animals at which treatment with D-gal had started. Hence, YT and
MT rats had significantly lower MDA levels in the liver, compared to AT ( $p<0.001$ in both cases). In the kidney, MDA concentrations in MT and AT rats did not differ significantly, but both were higher than the concentration in YT rats ( $<<0.001$ for both) (Fig. 5).

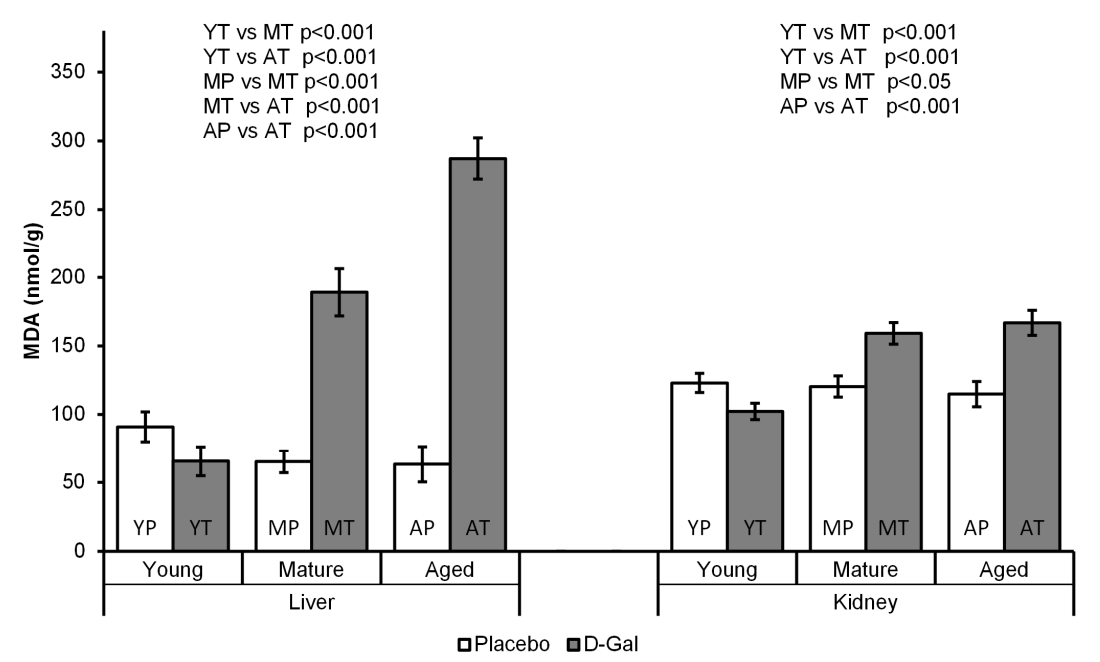

Fig. 5. Malondialdehyde levels in liver and kidney (MDA, mean $\pm \mathrm{SE})$. Abbreviations for groups are the same as in Figure 1.

Table 1. Ratio $R=\mathrm{SOD} /(\mathrm{GPx}+\mathrm{CAT})$.

\begin{tabular}{lcc}
\hline Group & R-Liver & R-Kidney \\
\hline Young placebo $(Y P)$ & 0.4300 & 0.3500 \\
Young treated $(Y T)$ & 0.4711 & 0.3636 \\
Mature placebo $(M P)$ & 0.6669 & 0.4294 \\
Mature treated (MT) & 0.8458 & 0.5108 \\
Aged placebo $(A P)$ & 0.5802 & 0.6273 \\
Aged treated $(A T)$ & 0.7514 & 0.4995 \\
\hline
\end{tabular}

* Ratio of enzyme activities $R=\mathrm{SOD} /(\mathrm{GPx}+\mathrm{CAT})$, represents equilibrium between formation of hydrogen peroxide from superoxide dismutation and its decomposition by other enzymes (GPx and CAT).

The relationship between antioxidant enzymes in liver and kidney

Changes in the equilibrium between the formation of hydrogen peroxide from superoxide dismutation and its decomposition by other enzymes (GPX and CAT) are expressed by the ratio $R=\mathrm{SOD} /(\mathrm{GPx}+\mathrm{CAT}) \quad$ (Table 1$)$. This ratio was significantly different when the values for MT and AT livers $(p=0.002)$ and kidneys $(p=0.011)$ were compared to the values of their placebo counterparts. In AT liver, this tendency was additionally corroborated by a positive correlation between SOD and CAT $(r=0.841, p=0.036)$.
Significant positive correlations between the levels of lipid peroxidation products (MDA) and the value of the ratio $R$ were observed in MP livers $(\mathrm{r}=0.983, \mathrm{p}=0.0004)$ and kidneys $(\mathrm{r}=0.869, \mathrm{p}=0.024)$ and AP livers only $(\mathrm{r}=0.865, \mathrm{p}=0.026)$. Moreover, the positive correlations between the liver ratio $R$ and MDA in mature $(\mathrm{r}=0.841$, $\mathrm{p}=0.036)$ and aged placebo rats $(\mathrm{r}=0.946, \mathrm{p}=0.004)$, were persistent even after the treatment with $\mathrm{D}$-gal $(\mathrm{r}=0.872$, $\mathrm{p}=0.025 ; \mathrm{r}=0.912, \mathrm{p}=0.01$, respectively). On the other side, the negative correlation between MDA and SOD $(\mathrm{r}=-0.958, \mathrm{p}=0.002)$ in YT liver and MDA vs CAT $(\mathrm{r}=-0.916, \mathrm{p}=0.01)$ in MT liver, once again potentiate the disintegrative potential of the D-gal on antioxidant equilibrium. In the kidneys, there were no significant correlations among studied variables after treatment with D-gal.

\section{Discussion}

The examined parameters were aimed to give us insight into whether the age of the rats at the start of D-gal treatment should be taken into consideration, regarding the antioxidant status of the subsequently established animal models of aging. In contrast to the general consensus, our results showed no significant changes in the examined antioxidant status (SOD, CAT and GR activity) in function of natural aging. 
Additionally, GPx activity was higher in mature and aged rats compared to the group of young animals. In our experiment, the absence of a decline in antioxidant enzyme activity could be explained in view of the age of the animals in all three groups of rats. Our previous results (Hadzi-Petrushev et al. 2011, 2012) have shown that GPx activity in liver and kidney decreases only after 18-20 months of age and CAT activity remains unchanged. In some way, this is an expansion of the results of Tian et al. (1998) who have shown that GPx activity in kidney decreases only after 24 months of age and does not change in the liver. GPx activity may be preserved due to the fact that aging is not necessarily associated with changes in the level of GSH (Kasapoglu and Ozben 2001) and the increased antioxidant enzyme activity represents an adaptive response to increased levels of oxidative products. In this manner, a decrease in one antioxidant may be compensated by an increase in another, maintaining relatively sufficient antioxidant protection in the cells (Rikans et al. 1992). For example, researchers have reported that $50 \%$ of SOD and up to $70 \%$ of CAT activity could be inhibited in isolated hepatocytes and still this antioxidant capacity is sufficient to withstand experimentally induced oxidative stress (Orr et al. 1992, Rikans et al. 1992). Also, Amstad et al. (1991) reported an overproduction of SOD in epidermal cells sensitive to superoxide and hydrogen peroxide, whereas cells with overproduction of CAT were protected against the effects of oxidants. Such protective effect of CAT was confirmed in our study, as we found significant increase in its activity only in senescent mature liver. Further, in mature and aged senescent livers we observed positive correlation between increased ratio $R=\mathrm{SOD} /(\mathrm{GPx}+\mathrm{CAT})$ and increased MDA. These results may support the theory of contribution of the antioxidant enzymes to the oxidative stress in the senescent rats, due to decreased SOD and GR activity. Moreover, the significant increase of MDA during senescence (MT and AT), found in this study, corroborates our hypothesis that the balance of the oxygen metabolism is compromised in both liver and kidney. In this sense, the negative correlations between MDA and SOD in YT livers and MDA and CAT in MT livers represent an additional support to our claim.

On the other side, in the case of aged rats, our results did not show significant differences in MDA levels in comparison to their younger counterparts. It has already been shown that lipid peroxidation of brain and liver, expressed as MDA, shows no significant differences among rats of different ages (Tian et al. 1998) and also no relationship was found between MDA levels and age in humans (Block et al. 2003). Nevertheless, these data do not exclude increased MDA production in relation to aging, as MDA may be subjected to rapid degradation, i.e. high turnover, so it is not possible to detect significant accumulation in chronic conditions (Holmes et al. 1992). Our data from the D-gal treated groups of rats, showed that starting the treatment at different age (3 or 15 months), could lead to the establishment of animal model of aging that completely fulfills the accepted profile of senescence, regarding the antioxidant enzyme activity and the level of MDA as marker of lipid peroxidation.

The increase in GPx activity after D-gal treatment in our experimental groups of mature and aged rats is in agreement with the consideration that the oxidative status of the cells primarily regulates the gene expression and the activity of antioxidant enzymes (Pahl and Baererle 1994). The fact that the increase in MDA levels in mature and aged D-gal treated rats was followed by an unchanged GPx activity, leads to a reasoning that either the response of GPx to increased pro-oxidant conditions is limited or the lack of change in GPx activity is a reason for increased MDA levels. Also, GPx per se is not an efficient decomposer of hydrogen peroxide (Lopez-Torres et al. 1993) and the absence of appropriate change in CAT activity in conditions of increased ROS may impair the capacity of the antioxidant enzyme system, leading to increased MDA levels.

The absence of significant D-gal-related changes in our group of young rats could be observed in the light of the mandatory attention that must be given to the developmental changes and the influence of aging on antioxidant enzymes (Wei and Lee 2002). The rate of free radical production in mitochondria increases with age in animal tissues (Perez-Campo et al. 1998, Wei and Lee 2002, Stojkovski et al. 2013) and the aforementioned results may be elucidated by the presence of low ROS production and better balance between the free radical scavenging enzymes in young tissues, which is very important for the cellular resistance to oxidative stress. In this direction, Kasapoglu and Ozben (2001) reported the presence of chemically modified enzymes with decreased catalytic efficiency in aged tissues. Further, Zhang with coworkers (2010) published that the activities of mitochondrial respiratory chain components (complex I, II, III and IV) in rats are reduced in D-gal-induced mimetic aging, when the D-gal treatment is started at the 
age of 5 months. Different studies (mainly performed on mice), corroborate our results, highlighting the importance of the starting age of the animals in relation to D-gal induced senescence. In this direction, $\mathrm{Xu}$ et al. (2009) reported that 3 and 6 months old mice are more suitable for establishing a mimetic ageing model compared to 1.5 months old mice. Regarding the use of rats, equivalent study has not been performed but experimental data showing increased MDA level, and decreased SOD and CAT activity is characteristic for animals of various ages at the start of the treatment (Lei et al. 2008, Liu et al. 2013).

The pathophysiological changes during natural and D-gal induced aging are related to the production of ROS and oxidative stress and it is obvious that rats of different age react differently to D-gal treatment. The pro-oxidant/antioxidant balance is successfully represented and can be assessed by the antioxidant enzyme activities and the level of lipid peroxidation. As it is shown by our study, in the D-gal model of accelerated aging, the changes in the antioxidant enzyme activities are not only under the influence of the D-gal overload, but also depend on the developmental stage of the animals. Senescence manifestation in old rats (15 months age) was quite unclear and the changes in the examined parameters were less consistent compared to the case of mature rats. Conversely, some of the D-gal induced changes in young rats (1 month age) were not considerably dissimilar to the changes observed in mature rats. However, it is reasonable to favor the choice of mature rats for the process of accelerated aging considering their complete organ and body differentiation in contrast to the possibility of additional changes relating to the natural maturation in young rats (Stuart et al. 2001, Kwekel et al. 2010). In general, this implies on the existence of optimal starting age of treatment for the establishment of D-gal-induced aging model in rats. In view of the enzymatic antioxidant status and the level of lipid peroxidation, the obtained results indicate that, in our experimental settings, the mature rats ( 3 months age) appeared to be the most appropriate for the development of an animal model of aging.

\section{Conflict of Interest}

There is no conflict of interest.

\section{References}

AMSTAD P, PESKIN A, SHAH G, MIRULT ME, MORET R, ZBINDEN I, CERUTTI P: The balance between $\mathrm{Cu}, \mathrm{Zn}$-superoxide dismutase and catalase affects the sensitivity of mouse epidermal cells to oxidative stress. Biochemistry 30: 9305-9313, 1991.

ANAND KV, MOHAMED JAABIR MS, THOMAS PA, GERALDINE P: Protective role of Chrysin against oxidative stress in D-galactose-induced aging in an experimental rat model. Geriatr Gerontol Int 12: 741-750, 2012.

BANJI D, BANJI OJ, DASAROJU S, ANNAMALAI AR: Piperine and curcumin exhibit synergism in attenuating D-galactose induced senescence in rats. Eur J Pharmacol 703: 91-99, 2013.

BLOCK G, DIETRICH M, NORKUS EP, PACKER L: Oxidative stress in human populations. In: Critical Reviews of Oxidative Stress and Aging: Advances in Basic Science, Diagnostics and Intervention. CUTLER RG, RODRIGUEZ H (eds), World Scientific Publishing, Singapore, 2003, pp 870-880.

CLAIBORNE A: Catalase activity. In: CRC Handbook of Methods for Oxygen Radical Research. GREENWALD RA (ed), CRC Press, Boca Raton, FL, 1985, pp 283-284.

HADZI-PETRUSHEV N, HRISTOV K, JANKULOVSKI N, MLADENOV M: L-2-oxothia-zolidine-4-carboxylate influence on age- and heat exposure-dependent redox changes in rat's blood plasma. J Physiol Sci 6: 437-442, 2011.

HADZI-PETRUSHEV N, JANKULOVSKI N, MILEV M, FILIPOVSKA P, GAGOV H, GJORGIEVSKA E, MITROV D, SOPI R, HRISTOV K, MLADENOV M: L-2-oxothiazolidine-4-carboxylate influence on ageand heat exposure-dependent peroxidation in rat liver and kidney. $J$ Therm Biol 37: 361-365, 2012.

HALLIWELL B: Reactive oxygen species in living systems: source, biochemistry and role in human disease. Am J Med 91: 3C14S-3C22S, 1991.

HE M, ZHAO L, WEI MJ, YAO WF, ZHAO HS, CHEN FJ: Neuroprotective effects of (-)-epigallocatechin-3-gallate on aging mice induced by D-galactose. Biol Pharm Bull 32: 55-60, 2009. 
HO SC, LIU JH, WU RY: Establishment of the mimetic aging effect in mice caused by D-galactose. Biogerontology 4: 15-18, 2003.

HOLMES GE, BERNSTEIN C, BERNSTEIN H: Oxidative and other DNA damages as the basis of aging: a review. Mutat Res 275: 305-315, 1992.

KASAPOGLU M, OZBEN T: Alterations of antioxidant enzymes and oxidative stress markers in aging. Exp Geront 36: 209-220, 2001.

KUMAR A, PRAKASH A, DOGRA S: Centella asiatica attenuates D-galactose-induced cognitive impairment, oxidative and mitochondrial dysfunction in mice. Int J Alzheimers Dis 2011: 347569, 2011.

KUMAR D, RIZVI SI: Plasma paraoxonase 1 arylesterase activity in D-galactose-induced aged rat model: correlation with LDL oxidation and redox status. Aging Clin Exp Res 26: 261-267, 2014.

KWEKEL JC, DESAI VG, MOLAND CL, BRANHAM WS, FUSCOE JC: Age and sex dependent changes in liver gene expression during the life cycle of the rat. BMC Genomics 11: 675, 2010.

LAWRENCE RA, BURK RF: Glutathione peroxidase activity in selenium deficient rat liver. Biochem Biophys Res Commun 71: 952-958, 1976.

LEI M, HUA X, XIAO M, DING J, HAN Q, HU G: Impairments of astrocytes are involved in the D-galactose-induced brain aging. Biochem Biophys Res Commun 369: 1082-1087, 2008.

LIU YY, NAGPURE BV, WONG PT, BIAN JS: Hydrogen sulfide protects SH-SY5Y neuronal cells against D-galactose induced cell injury by suppression of advanced glycation end product formation and oxidative stress. Neurochem Int 62: 603-609, 2013.

LOPEZ-TORRES M, PEREZ-CAMPO R, ROJAS C, CADENAS S, BARJA G: Simultaneous induction of SOD, glutathione reductase, GSH, and ascorbate in the liver and kidney correlates with survival during aging. Free Radic Biol Med 15: 133-142, 1993.

LOWRY OH, ROSEBROUGH JN, FARR LA, RANDALL JR: Protein measurement with the Folin phenol reagent. J Biol Chem 193: 265-275, 1951.

MARKLUND S, MARKLUND G: Involvement of superoxide anion radical in the autoxidation of pyrogallol and a convenient assay for superoxide dismutase. Eur J Biochem 47: 469-474, 1974.

MLADENOV M, GJORGOSKI I, STAFILOV T, DURIDANOVA D: Effect of vitamin C on lipid hydroperoxides and carbonyl group content of rat plasma depending on age and acute heat exposure. $J$ Therm Biol 31: 588-593, 2006.

NAVARRO A, GOMEZ C, LÓPEZ-CEPERO JM, BOVERIS A: Beneficial effects of moderate exercise on mice aging: survival, behavior, oxidative stress, and mitochondrial electron transfer. Am J Physiol Regul Integr Comp Physiol 286: R505-R511, 2004.

OHKAWA H, OHISHI N, YAGI K: Assay for lipid peroxides in animal tissue by thiobarbituric acid reaction. Anal Biochem 95: 351-358, 1979.

ORR WC, ARNOLD LA, SOHAL RS: Relationship between catalase activity, life span and some parameters associated with antioxidant defenses in Drosophila melanogaster. Mech Ageing Dev 63: 287-296, 1992.

PAHL HL, BAERERLE PA: Oxygen and the control of gene expression. BioEssays 16: 497-502, 1994.

PANDEY KB, RIZVI SI: Markers of oxidative stress in erythrocytes and plasma during aging in humans. Oxid Med Cell Longev 3: 2-12, 2010.

PEREZ-CAMPO R, LOPEZ-TORRES M, CADENAS S, ROJAS C, BARJA G: The rate of free radical production as a determinant of the rate of aging: evidence from the comparative approach. J Comp Physiol 168: 149-158, 1998.

RACKER E: Glutathione reductase from bakers' yeast and beef liver. J Biol Chem 217: 855-865, 1955.

RIKANS LE, HORNBROOK KR: Lipid peroxidation, antioxidant protection and aging. Biochim Biophys Acta 1362: 116-127, 1997.

RIKANS LE, SNOWDEN CD, MOORE DR: Effect of aging on enzymatic antioxidant defenses in rat liver mitochondria. Gerontology 38: 133-138, 1992.

STOJKOVSKI V, HADZI-PETRUSHEV N, ILIESKI V, SOPI R, GJORGOSKI I, MITROV D, JANKULOVSKI N, MLADENOV M: Age and heat exposure-dependent changes in antioxidant enzymes activities in rat liver and brain mitochondria: Role of $\alpha$-tocopherol. Physiol Res 62: 503-510, 2013. 
STUART RO, BUSH KT, NIGAM SK: Changes in global gene expression patterns during development and maturation of the rat kidney. PNAS 98: 5649-5654, 2001.

TIAN L, CAI Q, WEI H: Alterations of antioxidant enzymes and oxidative damage to macromolecules in different organs of rats during aging. Free Radic Biol Med 24: 1477-1484, 1998.

WARD WF, QI W, REMMEN HV, ZACKERT WE, ROBERTS LJ, RICHARDSON A: Effects of age and caloric restriction on lipid peroxidation: measurement of oxidative stress by F2-isoprostane levels. J Gerontol A Biol Sci Med Sci 60: 847-851, 2005.

WEI H, LI L, SONG Q, AI H, CHU J, LI W: Behavioural study of the D-galactose induced aging model in C57BL/6J mice. Behav Brain Res 157: 245-251, 2005.

WEI YH, LEE HC: Oxidative stress, mitochondrial DNA mutation, and impairment of antioxidant enzymes in aging. Exp Biol Med 227: 671-682, 2002.

XU Y, WU T, JIN Y, FU Z: Effects of age and jet lag on the D-galactose induced aging process. Biogerontology 10: 153-161, 2009.

ZHANG X, LIU W, NIU X, AN L: Systemic administration of Catalpol prevents D-galactose induced mitochondrial dysfunction in mice. Neurosci Lett 473: 224-228, 2010. 